\title{
Diversity: Concept and Issues
}

\author{
Louafia Boukreris ${ }^{1}$, Ghania Ouahmiche ${ }^{2}$ \\ ${ }^{1}$ Department of Foreign Languages, University of Oran 2, Oran, Algeria \\ ${ }^{2}$ Department of Human Sciences and Islamic Civilization, University of Oran 1, Oran, Algeria
}

Email address:

wboureris88@gmail.com (L. Boukreris),ghaniaouahmiche@gmail.com (G. Ouahmiche)

\section{To cite this article:}

Louafia Boukreris, Ghania Ouahmiche. Diversity: Concept and Issues. International Journal of Language and Linguistics. Vol. 5, No. 1, 2017, pp. 15-24. doi: 10.11648/j.ij11.20170501.13

Received: November 29, 2016; Accepted: January 24, 2017; Published: February 22, 2017

\begin{abstract}
Diversity is an important issue of our present world representing strength or nuisance given the richness it supplies us with or the conflicts it engenders affecting the nation's social, cultural, political and management levels. Regarding the many issues associated with diversity, this paper explores linguistic diversity and the ways it has been dealt with according to whether it is considered as a resource requiring investment or a disturbance requiring strategies of management. If at far epochs linguistic diversity was so natural as to require no explanation, with the rise of state building movement, linguistic diversity became subject to state policy processing. Given the side effects resulting from policy implementation, trends of linguistic human rights and language diversity protection are developing though seemingly defend linguistic diversity nourish conflicts which may minimize if minority linguistic communities develop loyalty to the larger linguistic group by sharing equally social, political and economic benefits.
\end{abstract}

Keywords: Diversity, Attitudes, Language, Conflict, Resource

\section{Introduction}

The term diversity reveals the idea of variety, difference and opposition. This is what the universe is made up of. It is there within the vegetal, animal and human species. The latter case carries some other important differentiating factors that determine diversity among which the racial, cultural, ethnic, linguistic and religious ones used as a basis on which people self -categorize. In fact, people do identify themselves with a social group on cultural grounds, which in addition to lifestyle encompass religious and linguistic aspects. John Viscount Morley (1944:99) notes.

In common language we speak of a generation as something possessed of a kind of exact unity, with all its parts and members one and homogenous. Yet plainly it is not this.It is a whole in a state of constant flux. Its factors and elements are eternally shifting. It is not one, but many these generations [1].

In Ancient Greece, patricians were differentiated and opposed to plebeians and slaves. Feudal Europe distinguished Lords from fiefs and slaves. South Africa displays an example opposing the White and the Black. India offers a case of ritual purity and pollution. Similarly, North Ireland illustrates a religious case while Turkey offers an ethnic case associated to the Kurdistan community. The francophone and the Arabophone represent a linguistic case. Furthermore, diversity happens to be an everlasting phenomenon taking an endless diversifying process conceived in a variety of ways. Furthermore, as Ingrid Pillar $(2016,14)$ notes «... diversity including linguistic diversity - is a characteristic of all human societies ...However, the principle of universal social diversity is complemented by the principle of social stratification: the social meaning of linguistic diversity is rarely 'different but equal'; much more frequently linguistic diversity forms the basis for inequality [2]" that Abram de swam (2013) conceives in a form of language Pyramid

With regard to earlier generation of linguists linguistic diversity was so natural as to acquire no explanation. In connection with the idea, Sapir Edward (qtd in Andresen, Julie Tetel 2013:201), observes

... a human activity that varies without assignable limits ... from social group to social group, because it is purely historical heritage of the group, the product of longcontinued social usage. It varies as all creative effort varies - not as consciously perhaps, but none the less as truly as do the religions, the beliefs, the customs, and the arts of 
different peoples. Walking is an organic; an instinctive function ... speech is non-instinctive, acquired 'cultural' function [3].

In fact; the concept of diversity is conceived from different optical angles. From Terence (185-159 BC), the Latin comedy poet and an emancipated slave, and the author of the sententious saying "so many men so many minds" revealing the phenomenon of plurality and diversity as well as abundance and opposition to Saint John Perse (1887-1975), a French poet and diplomat, and the author of "God the scattered rejoins us in diversity", suggestive of variety and affluence, disorder and dispersion.

As regards attitudes, there are those who highly praise diversity as it represents the voice of nature and its boundless generosity to maintain liveliness of the human universe. Honoré de Balzac's "in the life of man there are no two moments of pleasure exactly alike, anymore than there are two leaves of identical shape upon the same tree.", and Segalen Victor's "Honorez les hommes dans l'homme et le reste dans sa diversité." i.e., Honor the man in the man and the rest in its diversity, all express fascination.

However, Ramakrishna reveals a quite negative opinion about diversity as it results from ignorance stating that Knowledge leads to unity as ignorance leads to diversity. Du Bos Charles (1882 - 1939) shares the same opinion believing that diversity is a source of discomfort and avows. "I am a unity that goes well or a diversity that goes wrong."

Apparently, diversity is a two-way switch involving either strength and weakness or energy of life. Quoting Pillar (op cit:2 “ ... lingistic diversity in many societies around the world is well-organized, frequently enumerated, and even celebrated. However, on the other hand, linguistic diversity is associated with a range of social ills and seen as something that needs to be contained, possibly even something to be fearful about. [4]

Diversity, which means variety, is also suggested by the terms multiplicity, plurality, profusion, richness, difference, discontinuity, irregularity, and heterogeneity. But as a social phenomenon, it is paired with capital and force or conflict raising and investment. In fact, this phenomenon is omnipresent everywhere in the world which is becoming increasingly diverse. For William Safran and J.A. Laponse (2014) linguistic diversity takes different perspectives which "...are mutually exclusive or competing."

Reflection on Man and his environment led to the development of scientific disciplines which intend to cover the various social and cultural aspects of human life. The scientific world will see then the birth of sociology around the $1^{\text {st }}$ half of the $19^{\text {th }}$ century and gradually branches ramified each having one area of concern and pouring into the quest to disclose the secrecy of the different domains of diversity.

Earlier, human diversity was dealt with according to group specificities. An attempt was made to classify human diversity on the basis of the common characteristics that individuals share. It involves a racial classification on the criteria most immediately apparent: leucoderm (white) melanoderm (black) and xanthoderm (yellow). However; people are different not only according to skin color, which is but a surface discriminating factor, but also to other sound factors related to their practices.

The search for diversity went beyond this point to penetrate the world of languages and cultures, and what they hold, control and transmit. This is what linguistics intends to study and within which the term diversity describes a situation where several intra or extra linguistic groups are in interaction displaying a range of cases among which multiculturalism, plurilingualism, languages in contact, language spread, language maintenance, language death, language revival, and language power.

Diversity, as a concept, was first introduced in the world of science in the $19^{\text {th }}$ century with specific emphasis on the human geography and biology. It has also been used both in public and political discourse since 1970. But the interests in linguistic diversity as a topic have been growing only over the last few years. Linguistic diversity, which is a universal capital for humanity and is at the same time coupled with cultural diversity, participates in the constitution and maintenance of the biodiversity. As a linguistic phenomenon, diversity has incessantly attracted man's opinion either as an admirable, exciting and inspiring phenomenon or as a disquieting one. Breton has a favorable concept of language diversity as long as it decompartmentalizes thoughts. Accordingly, languages do not express the same human experience, that is, as many languages as many civilizations. And so to speak, the preservation of language inheritance constitutes the preservation of the different civilizations and guarantees the continuity of history and serves as a point of reference in the global development.

As regards linguistic diversity, historically, the movement of people, contact of communities and man's inquisition about his environment to uncover its secrecy has been the main reasons for language spread and development. It still has important linguistic consequences today. As Shohamy, Elana Golberg (2006:1) reveals "Language is constantly evolving, taking different colors, shapes and forms by its different users, in a variety of situation, location and points of time [5]." Languages are humanity's most priceless cultural legacy. Each language provides a system of concepts which help us to understand reality, and thus, duty arises for protection through transmission. Thus defending languages and their diversity, particularly against the domination of a single language is more than defending cultures. In fact, it is defending life.

At far epochs, languages were given birth to, and engaged in contact situations. They also developed, diversified, died and might re-energize unremittingly within the societies which adopt them. As Steiner (qtd in G.S Elana 2006:1) argues, "In analogy of the organic, it (language) undergoes incessant change. Languages live and die. They manifest epochs of enrichment, of acquisition, of political-culturalliterary dominance, and epochs of diminution and decay [6]." As far as the phenomenon of languages in contact is concerned, the development of the means of transport, 
telecommunication services and emigrating movements participate to its acceleration implying shock and diversification of languages in the short, mid and long terms. As Nettle (op cit) observes "linguistic diversity is a product of expansions, movements, and organization of human societies through time [7]."

The number of languages existing in the world today amounts to some thousands. Precisely how many we cannot say. For the French Academy, the number of languages all over the world amounted to 2796 in 1929 . But the twelfth Ethnologue Magazine edition of 1992 reveals 6528. The Summer Institute of Linguistics, an organization which struggles for the least known languages, advances a number of languages equal to 6000 and reports that the linguistic inheritance is inequitably distributed. About half of the world population uses daily one of the eight languages most widely spread: Chinese (1, 2 milliard users) English (478 million), Hindi (437 million), Spanish (392 million), Russian (284 million), Arabic (225 million), Portuguese (184 millions) and French (125 millions).

However, Hagége (op cit) together with Luca CavalliSforza (1996) and Jean Louis Calvet (1998) reveal respectively 4 to 5000 languages in the world. Grimes speaks of 6,809 languages, (in F. Marti 2005:47). Asya Pereltsvaig (2012:11) amounts the number to 6500-7000.This mosaic of languages constitutes the subject matter of linguists who poured first in the classification of languages according to parental relationships existing between and among languages motivated by the reconstruction of the ancestor language. Crystal, David (1985) offers details about the genealogical method of classification.

Others poured into a classification method based on the structure of languages known as typological classification, a procedure, introduced first by A. Von Schlegel (in Crystal op cit:150). Linguists tried to inquire about the way the machine like language works. Within this approach four groups of languages were identified on the principles of being isolating, agglutinating, inflexional or incorporating. In addition, languages are graded according to their level of development ranging from non- written languages (that are locally used and limited to oral tradition) to languages of international communication. Of intermediate developmental levels, linguists identified the vernaculars and national languages. Nettle (1999) distinguishes three types of linguistic diversity: "individual": it corresponds to the number of languages spoken in the world, "Genetic": and it refers to the number of linguistic families in the world, and "structural": and it concerns the degree of variability in the grammatical structure of the world's languages.

The great diversity of languages the world witnesses has been developing along the human evolution in accordance to the surrounding environment of each group of individuals or communities. Within this context, two hypotheses were put forward to acquire more light about language change and evolution. In the $18^{\text {th }}$ century, Leibnitz Gottfried Wilhelm (1646-1716) believed that nature creates neither species nor absolutely distinct kinds: there has always been some intermediary which connects one to the other. As far as language is concerned, this suggests that all languages be they ancient or modern derive from a unique protolanguage on the basis of the monogenesis hypothesis.

Others believe in a plurality of languages and origins. Be it the first or the second: diversity remains a fact and a phenomenon that characterizes languages on the basis of the factor of change, a phenomenon that contributes to "pidginizing" or "creolizing" of a language as it is the case of modern Romance languages. This deconstruction/construction ascertains a language dynamics which is manifested by the emergence of varieties which engaged in a squeezing status game fostering the expressive potential as well as the power of its users who are status promotion revealing.

In the distant past, the linguistic landscape was rather more local. Language difference was not an issue. There was no majority to define minority. But with the rise of the nationalist tendency, which emerged in the sixteenth and seventeenth centuries in Europe, the idea of national identity began to build up. This was coupled to a growing desire to have access to the Bible in the vernacular, and thus, to a growing awareness of language issues. In addition to the religious factor, the linguistic one was integrated to define the idea of identity within limited borders.

With the State formation process disparate groups found themselves trapped within state boundaries and driven into a welding process for a cohesive nation. Of course, state nation builders elaborated policies preaching state homogeneity and exclusive loyalty. Nation State definition then fell into a geographical, linguistic, and cultural boundary. Among the three factors, the linguistic one happens to be the strongest formula, which serves the nation's survival while culture becomes an embedded substance in language and a whole that is indivisible.

Furthermore, languages and their respective cultures became the distinctive factors on the basis of which the world partition is conceived nowadays. The terms 'Anglophone', 'Francophone' and 'Arabophone' are used to refer to the different populations according to language use bearing the idea of development and power. This contributed to the interplay between power and language at the national and international levels and the implications of this on linguistic diversity.

As far as nation state building is concerned, to centralize power over the whole territory, and to control the situation, state builders invested in the choice of an official national language, which happens to be theirs for the construction of the nation state, and the satisfaction of their objectives. This constitutes a dis-investment in the other groups as well as a withdrawal from the whole in a self-categorization process. The era of nationalism thus created the concept of linguistic minority and majority correlating with minor and major languages, and, of course, dominated and dominant groups. This categorization was inevitable to the desire for national cohesion and homogeneity.

The stronger the nationalist ideology develops the greater 
the concept of linguistic minority intensifies to become a problem and a threat. Consequently, the pattern of power exercise with the notion of elite and prestige form of language varieties builds up and diversity co-existence becomes conflict rising. Accordingly, strategies to handle diversity become a must. The nation is not only wired to the claim of a political power' but its very nature assumes that all the individuals concerned have a lot in common and that all must leave behind, and forget many things, (Renan in Poutignat 1995: 37).

The issue of language diversity, as related to power exercise to prescribe a national identity, heartened governments to elaborate language and planning policies that all poured into the mono-identity construction which bears in itself a hidden recognition of troublesome diverse co-existing identities to which diverse languages correspond. Various overt and covert coercive measures are taken to wear away the diverse identities and restrict the use of the languages in question. In fact, language policy is simply what governments do officially through legislation, court decision, executive actions, and other strategic means such as education, urbanization, industrialization, modernization, and technological penetration to subsidize the selected language at the expense of the others which are driven into the dynamics of "laisser faire".

The selection of a norm to be used at the national and official level as well as those used both at the official, national and international level show some hegemonic effect on the excluded or minoritized languages. Such effects drive into erosion the whole human capital amassed within these languages and disturbs the inner man in the long run. There is a close bonding between every individual and his language in such a way that language seems to mould the inner man. Georges Mounin (1968:71) in his quest for "what a language communicates" believes language to be the sum set of experience we have of the non-linguistic reality at least shared by users of the same language and that this linguistic reality is not conceived in the same manner in the other languages. To each language corresponds to a particular data organizing of the experience requiring a new way of analysis

Language diversity maintenance is equated with diversity of opinion and different world pictures. Substituting a language by another implies formatting the inner individual to inject other values and concepts. This operation constitutes a certain worry even in the case of a foreign language acquisition process. The acquisition of a foreign language implies a new semantic system and so a new way of thinking and feeling and the greater the differences between the two languages the greater the difference of thought and reasoning This creates some psychological, social, and cultural incidence that build up to constitute a self-rejection phenomenon that is commonly known as "self-hatred" or a rebel force which orbits around self-categorization. This is one of the side effects emerging when passing from one language to the other causing a change in the attitudes and conceptions of the inner man's universe, thus disturbing his mental files mainly when the native language and all values it holds are not deeply rooted in the inner man.

In fact, language is conceived as a prism through which users are bound to see the world. The lines of thought developing among psychologists, philosophers, anthropologists and linguists including Crystal's (1985) coordinates, that is, (language and thought), (language and reality) focus on the question whether there are universals lurking behind language or whether language frames our thinking. Georges Mounin (op cit) traced it back to B. L. Whorf who argues "we dissect nature along lines laid down by our native languages [8]." and to W. Von Humboldt / Guillaume de Humboldt (1767-1835) who as reported by Crystal (1985:151) signaled a linguistic instability justified by "the changing mental power of the users of language [9]."

\section{Approaches to Linguistic Diversity}

Languages accompany human groups. They either disappear with them, or spread on vast territories according to the group's size and its readiness to move beyond its place of origin. As a consequence, language death or ability to develop is intimately related to its users. Languages do have a competition feature to resist death, but this happens in view of the basis of dominating and dominated context, and the lack of means dominated ones suffer from to resist the appalling pressure of the dominating ones.

This natural endogenous competition among languages opposing dominant to dominated languages has been the object of a growing interest of both language governmental and non-governmental agencies. Worry seems to be concentrated on the minority languages, which are under the threat of disappearance. It is argued that linguistic diversity is a human resource capital, which is as important as natural resources and contributes to the human welfare. Thus, there is a felt need to protect, support, and promote minority languages. However, the approach to linguistic diversity has taken various orientations depending on the planned goals, which give the issue a complex aspect. Diversity is not approached principally on the basis of language threat only. Any act oriented towards linguistic diversity combines in a varied overlapping manners with communication, power, representation, culture, social identity, geography, and politics. This is because underlying motives feature the concerns.

Language is taken from different optical angles. It can be approached from instrumental, ethnocultural and language rights objectives as well as ecological, political and economic ones. The instrumental approach focuses on the functional aspect of language as it represents a tool for communication and transmission of the cumulated knowledge capital, an identity marker charged with material and /or symbolic values. The angle, from which it is interpreted, depends up on the motivations of language advocates. In fact it is viewed as any tool which requires constant care and development for more efficient and long term use.

The ethnocultural approach is oriented towards a micro vision representation. It seeks a restricted group identity, 
which can be taken from exclusive or inclusive perspectives. This is relevant to cases when social changes and political strategies threaten the wearing away of the subcultures which may even develop to an ethnic cleansing process giving rise to resisting attitudes against the exogenous domination. The focus on the cultural attributes that maintain the ethnic boundaries becomes an instrument to justify claims of ethnic belonging that frequently develop into conflicts seeking the desire to maintain diversity at the local, national, or international levels. For such a purpose, strategies are put in place to protect and preserve diversity. Language right approach is seen as a way to allow minority groups to enjoy their rights to practice their language varieties. This does not guarantee diversity maintenance. It is as if imposing a "stationary status" upon the minority linguistic group with a museum like role. Enjoying linguistic rights implies promotion, and therefore changes occur on the language status level through short, mid and long term whatever the policy be it planned or not. This leads to consider the ecological approach which considers language as any living species contributing to the balance and maintenance of the eco-system or the natural world. The ecological approach struggles for the defense of the universe linguistic capital and the promotion of the various languages threatened by death.

This is partly because the social, economic and political changes of the environment are affecting greatly the ecolinguistic landscape. Languages are involved in a displacement process which drives further back minority languages which undergo register gradual cleansing or obsolete status occurring when inter-generational communication fails its transmission mission. As the environment is constantly undergoing changes which influence undoubtedly language, diversity maintenance becomes an instrument to protect the universal capital. In view of that, minority groups are attributed a maintenance role rather than a prestige one in terms of language use representing a kind of language rare resource storage and conservation.

Language use also relates to the guaranteed services and material gains users benefit from. Indeed, Man is in a constant worry of socioeconomic mobility. Though preserving rights for minority groups for psychological, cognitive and spiritual survival seem paramount, it also maintains exclusion and imposes enclosure within a determined frame of development. Promoting minority groups for a linguistic diversity maintenance mission is rather interpreted as a strategy to clear the stage of competition for the supremacy of the dominant languages. This nourishes the idea of keeping ideal conditions for the stratification and statuses of languages. Dominant languages will be enjoying a kind of intrinsic superiority, which allows the maintenance of the language hierarchy, and, unsurprisingly the domination /subordination relation among the social groups, the communities or nations.

This leads to consider the aspect of power lurking behind the approach of global diversity. Whatever the approach, language is a question of policy and power exercise upon smaller or larger social groups from an inter-ethnic, intercommunity, national or international point of view. The political response to the issues varies accordingly. Issues of language are never neutral and do not target the masses' interests. Power is an unavoidable fact. Language diversity is rather instrumentalized and conceived from a dominance angle. Diversity itself escapes control. Dominant languages themselves tend to diversify and linguistic diversity activism represents a potential market for power maintenance, and distribution, that is, power chart configuration.

Language diversity takes different views. As a symbol, it plays an influential and fundamental role in society, but it happens that this potential is not all the time wholly and equitably acknowledged in the case of all languages at the moment language becomes the subject of decision makers. For purposes of organizing communication among members or groups of a community, decision makers generally favor unity of language of communication rather than diversity. However, outside the issue and the idea behind national language, which supposedly means to smooth the progress of unity of communication and promote a sense of belongingness among the different members and groups that happen to constitute one geographical entity, language can also cause group dislocation. This is because at the moment one variety is retained for national and official communication, the symbolic aspect of language becomes charged with the idea of exclusion. In the majority of cases, the community having a variety of language experiences this as a linguistic discrimination. As a result, the homogenous approach faces the heterogeneous one, and very frequently, communities are driven into a situation of language conflict. The uniting assets that a diverse community can invest on for purposes of unity are trapped within a climate of resistance and rejection.

In the case of policy makers, it is not usual to consider language as a major instrument in national integration. Rather, for national unity purposes, fractions of a community sharing the same geographical borders need to abandon the idea of having their own language. However, language has a wide role than this and is value laden. Value cannot be reduced to a unifying role and chauvinistic feeling. Language is a resource for a society. Nation -building cannot be barely limited to language communicative function. Language can be viewed from other angles. Using the same language on no account can be a crucial or a unique satisfactory condition for national integration. Wisdom requires that belongingness be promoted when other unity inducing factors are policy centered. Factors such as equity, fairness in the management and distribution of the nation's resources, respect for the rights of all citizens, opportunity for participation in the system, for social mobility and self- actualization as well as equal access by all the citizens to benefits incoming from the state. These must be guaranteed on the basis of rational and measurable criteria. In fact, the communication service, the knowledge, social and economic gains a language offers influence the individual's decision of adoption for integration motivation purposes to benefit from these advantages. 
Language is also one of the nation's resources to be used for the nation's profit and protected for the same purpose. Language needs to be conceived as any material natural resource that a country processes for the health of the nation. C. Baker and Sylvia Prys Jones (1998:283) believe "just as water in a reservoir and oil in the oil-fields are preserved as basic resources and commodities (...) languages are a natural resource that can be exploited for cultural, spiritual and educational growth as well as economic commercial and political gains [10]." Language choice and planning obeys economic strategies as any other resources in the nation's economy are planned and consumed. That is, language is that commodity, which is subject to cost benefit analysis and gains. The cost can be both determined according to macro benefits for the nation and micro ones for an individual language user. Some questions can come to mind namely, what does a country gain or lose by adopting any of the indigenous languages or an important language as its national official language? What sacrifice and for what gains is someone or a community ready to make for one language rather than the other, and what importance and place is given to the other languages or varieties, which are not selected. Certainly, the gains must outweigh the cost. Myrjana N. Daniel and N. Nelson (2003, 375-376) argue:

Social and political conditions could amplify or diminish language's salience as identity markers. If we admit that giving up an ethnic language can lead to, or is the result of, ethno- cultural dislocation, then we could predict that political conflicts will strengthen the ethnic groups' desires to maintain separate identity and thus preserve their distinct language(s). At the opposite, peaceful coexistence and social prosperity would probably weaken ethnic barriers and would possibly divest ethnic languages of their identity value [11].

This led scholars to view language and language diversity from three other different angles: as a problem, a right or a resource. In the first case, Language diversity is experienced as conflict rising feeding ethno-cultural and linguistic awareness in which case coercive actions are taken at the national level. In the words of Baker, C (2011: 353), "language is sometimes connected with national or regional disunity and intergroup conflict. Language is thus also viewed as causing less integration, less cohesiveness, more antagonism and more conflict in society [12]" Language as a right orientation focuses on the right of minorities to enjoy their human rights in using their respective language varieties. As regards Baker (op cit: 378 ), this trend "... will argue that language prejudices and discrimination need to be eradicated in a democratic society [13]." An alternative orientation to language as a problem and as a right is the idea of Language as a personal or national resource. An impressive and steady leap forward has been made in the field of linguistics. Recent development in cognitive sciences, developmental psychology, behavioural sciences have enlightened further the understanding of language related problems, improved tremendously language learning and acquisition and impacted positively in reshaping the attitudes towards the acceptance of linguistic concerns formulated by language variationists.

These breakthroughs in sociolinguistics inquiry have also had a powerful impact on the attitudes of decision-makers towards linguistic diversity. Henceforth linguistic diversity is no longer perceived as a societal pathology or deficit but as invaluable resource upon which nations can draw profitability socially, culturally, and economically. For Haugen Einar (qtd in Tove Skutnabb-Kangas, 2000:211), it is "... a resource of novel delights and subtle experience, a blessing [14]." Nyati L. Ramahobo (2004:29) on his turn argues, "When linguistic diversity is viewed as resource policy statements in status planning would be geared towards the development, preservation and use of as many languages as possible [15]." The centrality of language and its importance are stressed also by Lo Bianco (1987), one of the architects of language policy in Australia, "As the primary means of interpreting reality, language becomes a basic code to cultural evolution and change, and therefore becomes a code for the unique experience of different cultural groups. Language is a resource of group and cultural identity ... Languages is the product of cultural, artistic, economic and intellectual endeavours as well as the tools of them [16]."

As such, languages are valuable resources that require systematic organization, intelligent protection and coherent planning. In addition, other relatively recent sociolinguistic studies have focused upon languages as "natural resources" out of which nations can draw positively (Kaplan and Baldauf 1997). Therefore if it is admitted that languages are resources that may be equated with other natural resources, they then deserve intelligent and methodical planning for their preservation, development and enrichment through clearly designed rational and coherent language policies.

The recognition of language diversity as a resource serves as a friendly linguistic landscape to implement language policies. As Baker and Prys (1998:283) note "Within the language as a resource orientation, lies the assumption that linguistic diversity does not cause separation nor less integration in society. Rather it is possible that national unity and linguistic diversity can co-exist. Unity and diversity are not necessarily incompatible. Tolerance and co-operation between groups may be as possible with linguistic diversity as they would be unlikely when such linguistic diversity is respected [17]."

It is within this perspective that the French language policy adopted a flexible policy for the other varieties given that coercive measures rather caused resistance to the French language national policy. As Baker and Prys argue (op cit) "Languages may be viewed not only in terms of their economic bridge-building potentials but also be supported for their ability to build social bridges across different groups, bridges for cross-asfertilization between cultures [18]." As policy makers regard nation building from homogeny viewpoint, diversity stands as a disquieting factor instead of a friendly one. In their eyes, assimilation is a key to cast everyone into the same linguistic mould; however, this has liberated its own germs of disturbance. 


\section{Politics and Linguistic Diversity}

Politically speaking, language is a potentially powerful political instrument, which is alone capable of deciding politicians' and political parties' fate. It also serves as cement for communities in a search for autonomy and independence or as an issue among groups because some policies require disturbance to be realized. Indeed language emotions can be harnessed to divert people's attention from fundamental economic and political issues. As language policy ideals are usually associated with geopolitical visions, nationalists support national languages; regionalists support regional languages whereas international principles hope for a universal language. Likewise, diversity principles yearn for all languages to acquire equal statuses. However; this cannot be the case since the desired future language corresponds to the desired geopolitical future.

The issue wheeling around language diversity is not related to the phenomenon of language pluralism but rather to a socio-political and cultural recognition. Different languages with their corresponding diverse forms are what feature the language universe. But the problem is the homogenizing human action from the time social groups acquired power over other social groups and engaged in some practices, policies and later strategies to maintain the assets associated with power exercise. Underlying such a political context or along its expansion rose the phenomenon of diversity in search for recognition challenging the homogenizing tendencies. The international scene offers cases where the political power makes use of the linguistic weapon to impose itself.

When it comes to the linguistic situation during the communist régime, Albania illustrates the use of language as a means to control society and shows that the social revolution passes inevitably by a language revolution. The Tosk language was promoted to shift the Geg in the very first years. S. Maleshova, a Tosk intellectual and a former Minister of Press, Propaganda and Folk culture, forbade edition using the Geg language and ordered the teaching of the Tosk language in the north as early as the year 1945. The objective consisted of promoting a language policy destined to extend power over the whole territory including the north of Albania, that is, to conquer the north through language.

For normalization and standardization purposes, the government designed specialized language agencies intended to bring about a linguistic cleansing using Stalin's theory which states that when two languages are in confrontation, one of them is victorious at the expense of the other driving it to decline. In fact; the Albanese language played an important role in the history of the Albanese nation which was culturally and religiously diverse during the Ottoman domination. Language served then, as the only asset elected to conquer independence. Accordingly, language and culture constitute the very existence of a community and its means of assertion for self categorization.

Turkey represents another case. Two major objectives justify the language policy: a return to the Turkish etymological origin to give strength to the growing nationalism and a split-up from the Islamic civilization. Kamel Ataturk adopted the Latin alphabet to exhaust the Turkish language from oriental vocabulary to homogenize and separate Turkey from the Muslim world. Michel Bozdémir (1998:147) uses the terms "linguistic invention" to describe the case.

To bring to satisfaction such a decision, Kamel Ataturk bequeathed not only his funds in his will to realize the process by creating "the Society of the Turkish Language Studies" in 1932 to purify the Turkish language but organized an invitation of tender procedure to provide the Turkish language with equivalents for the foreign words. These measures are considered to be a linguistic policy to engage a civilization shutdown that Michel Bozdémir (op cit: 141) considers "a civilization cut" interpreted as an insertion strategy in Europe.

Czechoslovakia offers another case of language strategy. This country, which used to be considered linguistically homogenous, has recently been subdivided into different nation states with their corresponding languages. This instantaneous linguistic disintegration shows that the SerboCroatian language was simply an erroneous belief. The different speech communities regained their languages as the split occurred: The Serb for Serbia and Montenegro, the Croatian for Croatia and the Bosnian for the BosnieHerzégovine. In view of this, language is not only an instrument of communication but also a significant political stake. Similarly, this applies to the case of the Bosnian Serb Republika Spraker in 1996. The adoption of the Cyrillic script as the official script instead of the Latin script was resorted to as it capitalized on linguistic links with Serbia to establish linguistic distinctiveness between Bosnian Serbs and Bosnian Croat and Muslims who used Latin script.

Algeria also constitutes a case of language diversity which shelters two broad language diversities: the Arabic Language, the 'high' form of Arabic (Ferguson 1959), i.e., the "learned form", that I term the "school language" together with its corresponding oral varieties; and the Tamazigh language and its different varieties. In the case of Tamazigh, there are different varieties corresponding roughly to different regions: Kabylia, Aures, Mzab, and Ahaggar-Ajjer. It should be noted that all populations which settled in the Maghreb left their language imprints to varying degrees, but only these two broad varieties characterize officially the linguistic scene regardless of the foreign languages.

At the dawn of independence, the high form of Arabic is institutionally attributed a national and official status for nation state building objective calquing the state building European process. However, the Tamazigh language issue remained dormant causing different irruptions at different times along the process of the language policy implementation, known as the Arabization process. As Pillipp Strazny $(2013,34)$ argues "The policy that the Algerian government has adopted toward minority language groups has resulted in tensions among the different users [19]." Indeed, the Tamazigh issue surfaced strongly in the 
eighties, and after years of political unrest during which the Berber issue characterized mostly all language debates, a recent official decision adopted in April 2002 promoted the Tamazigh language to the status of the second national language. Along the language battle initiated long ago Tamazigh advocators are activating for the elaboration of written Berber.

No doubt that each individual constitutes a complex sum of different traits that emerge according to the medium within which the individual evolves, seeks or knits relations. The slightest incitement or spark is enough to explore them in one manner or the other when interacting with members of his group, community or society. The interaction may highlight the difference along an opposing or conflicting line leaving in the inner man traces that take refuge in the past or awaken in the present and may develop in the future.

These different traits constitute a coherent unity as far as the individual is concerned, but such a unity is deconstructed or disturbed according to the group in which the individual evolves. And because man is social by nature, the sum set of the whole diverse aspects of the group are automatically submitted to a chain reaction creating a hierarchy of bindings from the undesirable to the least and most desirable ones that either favor or disfavor group unity. Differences may rise to cause power to sneak covertly or overtly to generate in most of the time resisting attitudes, which can develop to a conflict. Furthermore, the promotion of the individual's cultural level as well as the rising of the national and ethnic consciousness contributes also to the upthrust of the differentiating-uniting assets which nourish conflict. In the case of language diversity, Breton (1998) believes it a potential reason of conflict for the states.

Indeed the linguistic factor is sufficient to ignite a conflict at the intra or extra level. Algeria represents a case of language conflict between the Arabic language and Tamazigh as previously mentioned. Europe and Russia offer other examples. As Heiko F Marten et al (2015:12) reveal:

...inside the European Union and in the Russian Federation the status of minority languages and their speech communities may range from fairly far-reaching minority protection regimes and autonomy regulations to a continuing lack of acceptance of linguistic and cultural diversity, where minority demands continue to be perceived as threats to nationhood. Minority-majority relations are always inherently subjects to conflicts which may include questions of access to important resources, wealth, educational opportunities, political and societal participations... [20]"

Even nowadays terror attacks attributed to radical Islam and independentists purposes have in the case of Russia, for example a language societal reasons. Though Russian is of a negligible presence within the multiethnic groups who have knowledge of their corresponding minority language in the Caucasus, it is used as the main language. This has developed into the Chechens'problem. Heiko F Marten et al (op cit: 16) report that" [the Chechen] minority people formed the titular nation of the break-away republic of Chechenya in the 1990's and two bloody wars have been fought in the area in which the language was spoken [21]". For Monica Shelley and Margaret Winck (2005:21) "many of today's political conflicts are also language conflicts; or they are political conflicts because they are language conflicts [22]". Shelley and wink (op cit) illustrate the case with the Catalan language. Indeed the Catalan speech community living mostly in the north of Spain and in the Balearic Islands with a fraction living in France underwent coercive decisions as is in the case of Spain which relegated the Catalan to a patois status excluded from education and media use mainly under Franco's era. This led to a guerrilla movements and armed regional conflict.

French and Flemish offer another case of a language conflict developing into a political one opposing two speech communities respectively. M. Hartig (1985:67) notes in the case of Belgium, which seems to have solved the linguistic problem, " ... occasional protests along the language frontiers [22]." Though, the Belgium authorities decided to form French, Flemish and German communities to resolve the never-ending linguistic problem to run the language and cultural affairs apart, the language issue remains a major issue in Belgium today. According to Liebset Hooghe (2003:83) "some people even think the language question could eventually split the nation into two [23]". The Flemish daily newspaper De Standaard predicted, "It may take a decade, or a generation, but the Belgium state is dissolving itself" Liebset Hooghe (op cit). Recently, the linguistic conflict has reappeared to take a political aspect, which manifests a linguistic problem as regards the Flemish group who feels the threat of marginalization and loss of political power. Any disequilibrium in the handling of the different groups' interests is declined into a conflict and a threat for linguistic dislocation and separation perspective. Within similar veins Shelley and Winck (op cit, 21-22) observe that "The tug-of-war between Flemish and Walloon has brought down governments in Belgium. These two languages ... will remain mutually hostile until the day when Belgians are made to feel that are getting equal treatment and a fair share of what the nation has to offer... [24]".

Another linguistic clash between French and English is illustrated by the Canadian case, which is a never-ending problem. Quoting Charles Boberg (2010: 3)

Despite [the] official guarantees, the practical status of English and French in Canada has never been equal, with English ascendant and French struggling to survive outside its main base in Quebec. Even within Quebec, many French Canadians by the mid twentieth century felt their language and culture to be threatened by a large and powerful English speaking minority... this situation contributed to the rise of a French Canadian nationalist movement in the 1960 s that posed a serious threat to Canadian unity [25].

While stressing the place of the French language in the life and destiny of Quebec, René Lévesque, former leader of the Quebec Party and Quebec Prime Minister, (qtd in Suzanne R (2015:32), strongly argues, "Being ourselves is essentially a 
matter of keeping and developing a personality that has survived for three and a half centuries. At the core of this personality is the fact that we speak French [...] To be unable to live as ourselves, as we should live, in our own language and according to our own ways, would be like living without a heart [26]."

Furthermore, Jaime Lluch (2014:133) reveals that the Liberal Party of Quebec clearly defends the identity of Quebec in his report issued in December 1996 stating that "Beyond any other consideration, what must be emphasized firmly is that the identity of Quebec is not negotiable. And to the extent certain measures seem to be indispensable ... they are not subject to negotiations ... the national Assembly reiterate solemnly and officially its role in the promotion and the protection of the essential characteristics of Québec's society, notably language ... [27]."

\section{Conclusion}

The problems that language diversity engendered in different parts of the world heartened the Algerian liberation movement group to adopt a choice, which would maintain the geographical oneness of the Algerian nation and the Arab-Muslim kinship. Thus, the geographical together with the religious and language factors were retained as the strong uniting candidates to fight colonialism and oppose the western world and its civilization. The fact that the Algerian elite who framed the national movement of liberation was of Arabic and Berber language background suggests that the choice of the Arabic language as a candidate for independence affirmation was not a case of majority and minority. It was rather a sound choice which sprung from a common accord to slash the policy of "divide and rule" the French colonial authorities sought in order to sever the Berber community from the Arab community.

If the consensus around the Arabic language during the colonial period was independence oriented as it constituted a shared and cherished purpose and outcome, the goals of independent Algeria were manifold., thus the way diversity was conceived was rather an adhoc treatment case. The post independence language agenda unveiled social, economic and political power perspectives causing an elite clash as related to the approach to language policy for fear that the Arab educated elite would detain the monopoly over the national affairs, and consequently subordinate and drain the Berber ethnic component. A feeling of mistrust developed among the influential members of the two elites affecting greatly not only decision taking but implementation of the policy as well. The authorities failed to see within the unifying language policy, the other facet of the coin that shelters forces of support and opposition the cultivation of which depends on how far equity is being observed at the different levels to generate social, economic and political stability. Kaplan and Baldauf (1997:164) state, "While language may be misused as an ideological weapon for power and dominance, it may also be a force for generating employment, development and ethnic harmony [28]".
Skutnabb-Kangas (1995) in his turn, holds that if "the rights of minorities are respected; there is less likelihood of conflict. [29]" (qtd in Katrin Bromber \& Birgit Smieja, 2004:67). Carol L. Schmid (2001:136) asserts that

Attitudinal differences between linguistic groups do not disappear, even in countries such as Switzerland with low levels of intergroup tension. We have identified a greater sensitivity among Romand ... and more critical view of language relations and less sympathy toward the language majority... nevertheless, in Switzerland there are mitigating factors such as pride in the Swiss state by both French and German Swiss, a general accommodating attitude of the majority language group to the Latin language minority and a common civic culture.

For Martin Pùtz (2004:68) "linguistic diversity is in no way causally related to conflicts, though of course language is a major mobilizing factor in contexts where an ethnic group feels itself threatened, and /or where ethnic and linguistic boundaries coincide with other borders along which access to power and resources is (unequally) distributed".

\section{References}

[1] Andresen, J. t. (2013): linguistics and Evolution: A developmental Approach. Cambridge: Cambridge University Press.

[2] Anthony, Liddicoat J. (2005): 'Corpus Planning: Syllabus and Materials Development' In Hinkel, Eli. Handbook of Research in Second Language Teaching and Learning,. London: Routledge, 993-1012.

[3] Baker, C. and Jones S. P. (1998): Encyclopaedia of Bilingualism and bilingual Education.Clevendon: Multilingual Matters.

[4] Baker, C. (2011): Foundations of Bilingual Education and Bilingualism $\left(5^{\text {th }}\right.$ ed). Bristol: Multilingual Matters.

[5] Balzac, Honoré de. (2012): Analytical Studies. Germany: English (eds)Tredition.

[6] Bianco, Joseph Lo. (1987): National Policy on Languages. Cambera: Australian Government Publishing Services.

[7] Boberg, Charles. (2010) the English Language in Canada: Status,History and Comparative Analysis. Cambridge: Cambridge University Press.

[8] Breton, Roland. (1998): Géographie des Langues. Alger: Casbah.

[9] Calvet, Jean Louis. (1998): La Sociolinguistique. Paris: PUF.

[10] Cavalli-Sforza, Luca. (1996): Genes, Peuples et Langues. Paris: Odile Jacob.

[11] Claude Hagégé. Halt à la Mort des Langues. (2000): Paris: Odile Jacob.

[12] Crystal, David. Linguistics. (1985): Great Britain: Penguin Books.

[13] Daniel, Nettle. (1991): Linguistic Diversity. Oxford: Oxford University Press. 
[14] Daniel, Odile. 'I'Unification Linguistique en Albanie' (1998): In Chaker, Salem. Langues et Pouvoir de l'Afrique du Nord l'Extreme -Orient. Ex en Provence: Edisud, 97-100.

[15] Georges, Mounin. (1968): Clefs pour la Linguistique. Paris: Seghers.

[16] Georges, Mounin (1963): Les Problemes Théoriques de la Traduction. Paris: Gallimard.

[17] Gouhier, Marie Anne. (1951): Du Bos Charles. Paris: Vrin.

[18] Hartig, Matthias. (1985): 'The Language Situation and Language Policy in Belgium' In William R. Beer, James E. Jacob. Language Policy and National Unity. New jersey: Rowman and Allanhed Publishers, 67-78.

[19] Hooghe, Liebset. (2003): 'Belgium from Regionalism to Federalism.' In Coakley, John. The Territorial Management of Ethnic Conflict. London: Routledge, 73-98.

[20] John, Viscount Morley. (1944):On Compromise. London: Thinkers library.

[21] KAS, deprez. (1987) 'LE Néerlandais en Belgique.' In Jacques, Maurais. Politique et Aménagement linguistiques. Paris: Le Robert, 49-120.

[22] Katrin Bromber, Birgit Smieja. (1996): Globalisation and African Languages: Risks and Benefits. Berlin: Moton De Gruyter.

[23] Knowles, Elizabeth. (2006): The Oxford Dictionary of Phrase and Fable. Oxford: Oxford University Press.

[24] Lluch, Jaime. (2014): Visions of Sovereignty:Nationalism and Accommodation in Multinational Democracies. Philadeiphia: University of Pennsylvania Press.

[25] Malmberg, Bertil. (1966): Les Nouvelles Tendances de la Linguistique. Paris: PUF

[26] Marti, F.(2005): Words and Worlds. Clevendon: Multilingual Matters.

[27] Martinet, André. (1961): Elémént de Linguistique Générale. Paris: Armand Colin.

[28] Michel, Bozdemir. (1998): 'D'une Langue Impériale à une Langue Nationale: Vicissitudes d'une Politique Volontariste en Turquie.' In Chaker, Salem. Langues et Pouvoir de l'Afrique du Nord à l'Extreme-Orient. Ex en Provence: Edisud, 139149 .

[29] Mirjana N. Dedaic, Daniel N. Nelson. (2003): At War with Words. Berlin: Walter de Gruyter.

[30] Monica Shelley, Margaret Winck. (2005): Aspects of European Cultural Diversity. London: Routledge.

[31] Nyati-Ramahobo, Lydia. (2004): 'The Language Situation in Bostwana.' In Richard B. Baldauf, Robert B. Kaplan. Language Planning and Policy in Africa. Clevedon: Multilingual Matters, 21-78.
[32] Pereltsvaig, A. (2012): Languages of the World: An Introduction. Cambridge: Cambridge University Press.

[33] Perse, Saint John. (2014): Collected Poems. Princeton: Princeton University press.

[34] Pillar, I. (2016): Linguistic Diversity and Social Justice: An Introduction to Applied Sociolinguistics. Oxford: Oxford University Press.

[35] Poutignat, p, Streiff-Fenart, J. (1995): Théories de l'Ethnicité. Paris: PUF.

[36] Pùtz, Martin. 'Can a Foreign Language be a National Medium of Education? Linguistic Ecology and Equality in Namibia.' (2004): In Katrin Bromber, Birjit Smieja. Globalization and African Languages: Risks and Benefits. Hague: Mouton De Gruyter, 65-84.

[37] Robert B. Kaplan, Richard B. Baldauf. (1997): Language Planning from Practice to theory. Clevedon: Multilingual Matters.

[38] Romaine, Suzanne. (2015) 'The Global Extinction of Languages and its Consequencies for Cultural diversity.' In Heiko F Marten et al. Cultural and Linguistic Minorities in the Russian federation and the European Union: Comparative Studies on Equality and Diversity. Germany: Springer,. 36-41.

[39] Saarikivi, J. and Toivanene, R. (2015): 'Change and Maintenance of Plurilingualism in the Russian Ferderation and the European Union.' In F. M. Heiko, Cultural and Linguistic Minorities in the Russian Federation and the European Union: Comparative Studies on Equality and Diversity. Germany: Springer, 3-30.

[40] Sapir, Edward.(2004.): Language: An Introduction to the Study of Speech. Mineola, NY: Dover Publications

[41] Shoamy, Elena Golberg. (2006): Language Policy:Hidden Agenda and New Approaches. Oxen: Routledge

[42] Skutnabb-Kangas, Tove. (2000): Linguistic Genocide in Education--or Worldwide Diversity and Human rights? New York: Routledge.

[43] Schmid, C. L. (2OO1): The Politics of Language: Conflict, Identity, and Cultural Plurilingualism in Comparative Perspective. Oxford: Oxford University Press.

[44] Strazny, P. (2013): Encyclopedia of Linguistics. UK: Routledge.

[45] Swami ranganathananda, Elva Linnea Nelson. (1991): Human Being in Depth:A Scientific Approach to Religion. New York: Sunny Press.

[46] Thomas, Louis Paul. (1998): 'La Dislocation linguistique comme Instrument de Pouvoir: l'Example de l'ExYougoslavie.' In Chaker, Salem. Langues et Pouvoir de L'Afrique du Nord l'Extreme-Orient. Ex en Provence: Edisud.109-122.

[47] William Safran, J. A. Laponse. (2014): Language,Ethnic Identity and the State. NY: Routledge. 